\title{
SCANNING PROBE MICROSCOPIC AND OPTICAL DETECTION OF DNA INTEGRATION WITHIN MULTICOMPONENT STRUCTURES ON Si SURFACES
}

\author{
V. Bukauskas, J. Babonas, A. Rėza, J. Sabataitytè, I. Šimkienè, and A. Šetkus \\ Semiconductor Physics Institute, A. Goštauto 11, LT-01108 Vilnius, Lithuania \\ E-mail: setkus@pfi.lt
}

Received 9 May 2008; revised 13 June 2008; accepted 18 September 2008

\begin{abstract}
Self-arrangement of DNA based structures on clean mica and modified Si surfaces is investigated by means of scanning probe microscope (SPM) and spectroscopic ellipsometry (SE) method. DNA strands are deposited from a colloidal solution on solid surfaces at room temperature. Surfaces of solid substrates and biomolecular structures are additionally modified by $\mathrm{Ag}$ nanoparticles. The self-arranged surface structures are visualized by SPM. The effect of the multicomponent structures on the optical response of complex hybrid structures is studied. Changes in the optical response of the hybrid samples are related to the contributions of self-assembled DNA-based structures and Ag nanoparticles on the Si surfaces. Binding of Ag nanoparticles to the DNA strands and formation of well-ordered structures on the surfaces with DNA are discussed.
\end{abstract}

Keywords: biomolecular structures, surface, self-assemblage, optical properties, scanning probe microscopy

PACS: 68.37.Ps, 78.68.+m, 81.07.Pr, 81.16.Dn

\section{Introduction}

During the last decade an interest in the development of self-arranged hybrid structures is increasing rapidly. Advantages of these structures are expected being originated from unique properties of biomolecules such as proteins, desoxyribonucleic acid (DNA), and redox enzymes [1-5]. Integration of the biomolecules within solid nanostructures introduces biochemical recognition in the technology and functioning of the devices. Components of electronic circuits, sensors, and actuators can be created by nanotechnology and selfassemblage of supramolecules [1,2]. Properties of solid nanoobjects can be significantly modified by biomolecules [3-5].

Self-assemblages of biomolecules are recognized as attractive templates for a large variety of hybrid structures [6]. Assemblies based on the $\alpha$-helix type molecules are frequently described in numerous reports (e. g., [6-11]). The assemblies are easily obtained due to a high stability of materials based on the $\alpha$-helix [6]. These materials are found acceptable to create new selfassembled materials, the properties of which can be tailored to specific conditions of application. Possibilities to make templates and scaffolds for assembly of minerals and inorganic materials such as metals have been recognized as the most attractive ways to make nanothin wires, interconnects, light emitting and light collection devices, sensors, and transducers. The fundamental understanding of molecular self-assemblage including adsorption, nucleation, and growth of two- (2D) and threedimensional (3D) structures is a key element in development, optimisation, and exploitation of the nanotechnologies.

Considering the $\alpha$-helix type biomolecules, DNA molecules are the most frequently used "building blocks" for assemblies of various dimensions between nanometres and micrometres $[1,2,7,8]$. The negative charge in phosphate backbone of DNA molecules is favourable for fastening metal nanoparticles and, consequently, for creating multifunctional and multicomponent nanostructures by binding together metal and semiconductor structures. Formation of complexes involving DNA can be successfully exploited in advanced technology if the mechanisms of the underlying selfassemblage processes are well described. Increasing interests to investigate these mechanisms are the main stimulus for numbers of studies reported during the last years [6-11].

From the above it follows that the self-formation of biomolecules depends critically on the interaction with the surface of the solid substrate. The biomolecules 
can form the covalent bonds by linking to the surface through silanole $(-\mathrm{O}-\mathrm{Si}-)$, amidine $(-\mathrm{NH}-(\mathrm{C}-\mathrm{O})-)$, phosphonate $\left(\mathrm{O}-\left(\mathrm{HPO}_{2}\right)-\right)$ or carboxyle $(-\mathrm{O}-(\mathrm{C}-\mathrm{O})-)$ groups [12]. For enhancing the linkage, the solid surfaces are usually modified favouring the formation of covalent bonds $[13,14]$. In order to modify the surface, $\mathrm{Si}$ substrate can be coated by (3-aminopropyl)triethoxysilane (APTES) [15].

The present study is focused on hybridization of DNA molecules with modified Si surfaces followed by binding Ag nanoparticles with the hybrid material. Structural, mechanical, optical, and electrical properties are investigated for the multicomponent surfaces at different stages of component assembling. Experimental investigation aims to describe comparatively large well-ordered hybrid assemblies on real surfaces and to identify intentionally used components in the assemblies.

\section{Methods and experiments}

The reference samples were prepared on standard mica substrates with very smooth surfaces on which $z$-dimension varies less than $\sim 1-2 \mathrm{~nm}$. On these substrates, DNA-based layer was deposited from colloidal solution. A drop of the solution was spread on the substrate. The substrate was kept still in laboratory atmosphere $(T=293 \mathrm{~K}$, relative humidity about $30 \%)$ for 15 minutes, then rinsed in a distilled water. Before the measurements, the substrate was dried in the laboratory atmosphere for about 24 hours. Several of these samples were covered by Ag nanoparticles from colloidal solution as it is described in the next paragraph.

Standard Si substrates $(n-\operatorname{Si}(100), \varnothing 5 \mathrm{~cm}$, resistance $0.5 \Omega \mathrm{cm}$ ) were typically used for deposition of combined hybrid structures. The samples were prepared by sequential deposition of silica, (3aminopropyl)-triethoxysilane $\mathrm{NH}_{2}\left(\mathrm{CH}_{2}\right) 3 \mathrm{Si}\left(\mathrm{OC}_{2} \mathrm{H}_{5}\right)_{3}$ (APTES), and a solution of polyvinylpropylene (PVP)covered $\mathrm{Ag}$ nanoparticles $(\varnothing \sim 5 \mathrm{~nm})$ on Si substrates. The $\mathrm{SiO}_{2}$ layer of $50-150 \mathrm{~nm}$ thickness was deposited on cleaned Si substrates by sol-gel spin on technique [16] and annealed at $300^{\circ} \mathrm{C}$ for $1 \mathrm{~h}$. On the top of silicacoated Si substrate the APTES layer was formed by immersing the sample into APTES solution $(5 \% \mathrm{v} / \mathrm{v})$ in ethanol for $30 \mathrm{~min}$ or $(1 \% \mathrm{v} / \mathrm{v})$ in toluene for $4 \mathrm{~min}$. The APTES-coated substrates modified in ethanol solution were washed in aqueous $1 \mathrm{mM}$ acetic acid $\mathrm{AcOH}$. The samples modified in toluene solution were repeatedly washed five times in toluene. After washing, the samples were dried at $50-60^{\circ} \mathrm{C}$ for $0.5-2 \mathrm{~h}$ in air or Ar at- mosphere. The APTES-modified substrate was washed in diluted $1 \mathrm{mM}$ acetic acid $\mathrm{AcOH}$. The hybrid sample DNA / APTES / $\mathrm{SiO}_{2}$ / Si was formed by drop casting of DNA in physiological solution and dried at room temperature for at least $10 \mathrm{~h}$. In the final step the hybrid sample was immersed in colloidal solution of PVPcoated $\mathrm{Ag}$ nanoparticles for $2 \mathrm{~h}$ and then dried in air. The as-prepared samples were washed in water ultrasound bath at $40^{\circ} \mathrm{C}$ for 20 min to remove the remains of chemical procedure.

In addition to complete $\mathrm{Ag} / \mathrm{DNA} / \mathrm{APTES} / \mathrm{SiO}_{2} / \mathrm{Si}$ and Ag / DNA / APTES / Si samples, the reference samples APTES / Si, APTES / $\mathrm{SiO}_{2}$ / Si, DNA / APTES / Si, and $\mathrm{Ag} / \mathrm{APTES} / \mathrm{SiO}_{2} / \mathrm{Si}$ were prepared and investigated. Along with sol-gel method, some other techniques (thermal annealing in air and oxidation in water) were also used for the formation of silica layer. However, it was found that uppermost APTES layer was making the most important influence on the properties of hybrid sample.

Structure of the sample surfaces was visualised by SPM. The images of the surfaces were obtained by SPM D3100 / Nanoscope IVa (Veeco, Digital Instruments). Standard contact and non-contact modes were used for description of topography and more sophisticated features of the sample surfaces [17-19]. Combined modes were used for mapping the electrical and mechanical properties of the hybrid structures during one scan.

Topography of the surfaces is recorded by measuring the horizontal and vertical position of the tip that is scanning the surface area along series of parallel lines. Vertical position of the tip varies with the surface height along the scan line in the contact mode because the tip is permanently engaged with the surfaces. Because the tip is continuously pressed by the cantilever over the surfaces, soft structures can be damaged during the contact scan. In the non-contact mode (Tapping Mode in the D3100) the cantilever is forced to oscillate at or near the resonance frequency in such a way that there is only an intermittent contact between the tip and sample during each oscillation period. The cantilever oscillation is reduced due to energy loss caused by the tip contact with the surfaces. The reduction in oscillation amplitude is used to identify and measure surface features. The root mean square (RMS) signal is determined by the SPM system. Since the RMS signal depends on the distance between the cantilever and surface, the feedback system adjusts the tip-sample separation to maintain constant amplitude of the oscillations. The feedback signal is proportional to the vertical variation of the surface profile. In addition to this type of data, a phase shift be- 
tween the actuating signal and oscillations of cantilever is measured during the same scan. It has been demonstrated that the phase lag is highly sensitive to variations of adhesion, friction, and composition of the surfaces [17, 19].

Electrical properties were characterized by distribution of electrical potential across limited area of the sample surfaces (Electric Force Microscopy, EFM) [20-22]. In surface potential detection mode of the SPM D3100, the effective surface voltage of the sample is measured by adjusting the voltage on the tip to match that of the surface, thereby minimizing the electric force from the sample. Conducting and non-conducting regions as well as regions of different metals will show contrast in the images of the potential due to contact potential differences.

Surface potential detection is a two-pass procedure where the surface topography is obtained by standard Tapping Mode in the first pass and the surface potential is measured on the second pass. The two measurements are interleaved: that is, they are each measured one line at a time with both images displayed on the screen simultaneously. On the first pass, in Tapping Mode, the cantilever is mechanically vibrated near its resonant frequency by a small piezoelectric element. On the second pass, the tapping piezo drive is turned off and an oscillating voltage $V_{\mathrm{AC}} \sin (\omega t)$ is applied directly to the probe tip. If there is a DC voltage difference between the tip and sample, then there will be an oscillating electric force on the cantilever at the frequency $\omega$. This causes the cantilever to vibrate, and the amplitude can be detected. If the tip and sample are at the same DC voltage, there is no force on the cantilever at $\omega$ and the cantilever amplitude will go to zero. Local surface potential is determined by adjusting the DC voltage on the tip $V_{\text {tip }}$ until the oscillation amplitude becomes zero and the tip voltage is the same as the surface potential. The voltage applied to the probe tip is recorded by the SPM and is used to construct a voltage map of the surface.

The hybrid samples prepared on Si substrates were characterized also by SE technique. Photometric ellipsometers with rotating analyzer [23] and photoelastic modulator of light polarization [24] were used in the spectral range of 250-800 $\mathrm{nm}$. The complex reflection was obtained from experimental data for complex reflection coefficient

$$
\rho=\frac{r^{p}}{r^{s}} \tan \Psi \exp (\mathrm{i} \Delta),
$$

where $r^{p}$ and $r^{s}$ are the Fresnel reflection components for light polarized parallel $(p)$ and perpendicular $(s)$ with respect to the plane of light incidence, $\Psi$ and $\Delta$ are the ellipsometric parameters, which determine the change of the amplitudes $\left|r^{k}\right|$ and phases $\delta_{k}(k=p, s)$ of the Fresnel reflection coefficients:

$$
\tan \Psi=\frac{\left|r^{p}\right|}{\left|r^{s}\right|}, \quad \Delta=\delta_{p}=\delta_{s} .
$$

The experimental data of ellipsometric parameters for complex hybrid samples were analysed in the frame of multilayer model. The sample was modelled by the stack of layers parallel to the substrate surface, each $i$ th layer being characterized by thickness $d_{i}$ and dielectric function $\varepsilon_{i}$. The optical response of the multilayer system was calculated by the transfer matrix technique [25] modelling the light propagation and introducing the 2D vectors for electric and magnetic fields, and taking into account the boundary condition on the interfaces [23].

For the reference samples, like APTES / Si, the spectral dependences of ellipsometric parameters were interpreted in the multilayer model making use of the database [26] for the dielectric functions of standard materials like $\mathrm{Si}$ and silica. In this case the thickness and the weight of sublayers were considered as adjustable parameters at fitting the modelled spectra to experimental ones. For complex hybrid samples, both dielectric function and thickness of sublayers were adjustable parameters in the fitting procedure. In this case, the spectral dependence of ellipsometric parameters $\Psi$ and $\Delta$ was described by contribution of three Lorentzian-type lines:

$$
\varepsilon(E)=\sum_{k} \frac{A_{k}}{E_{k}^{2}-E^{2}-\mathrm{i} E \Gamma_{k}},
$$

where $A_{k}, E_{k}$, and $\Gamma_{k}$ are the amplitude, the energy, and the width of $k$ th Lorentzian line, respectively, and $i$ is the imaginary unit.

\section{Results}

\subsection{Structural studies}

Separated DNA structures were identified in the corresponding reference samples by SPM scanning. Typical SPM images of the surfaces for samples DNA / mica are illustrated in Fig. 1. Shape in plane and variations in height can be analysed in Fig. 1(a) where variations in height over the surfaces are visualised in the greyscale method. Ball and thread like objects were found on the mica surface of the reference samples by SPM scanning. Thread like structures in the SPM images in 


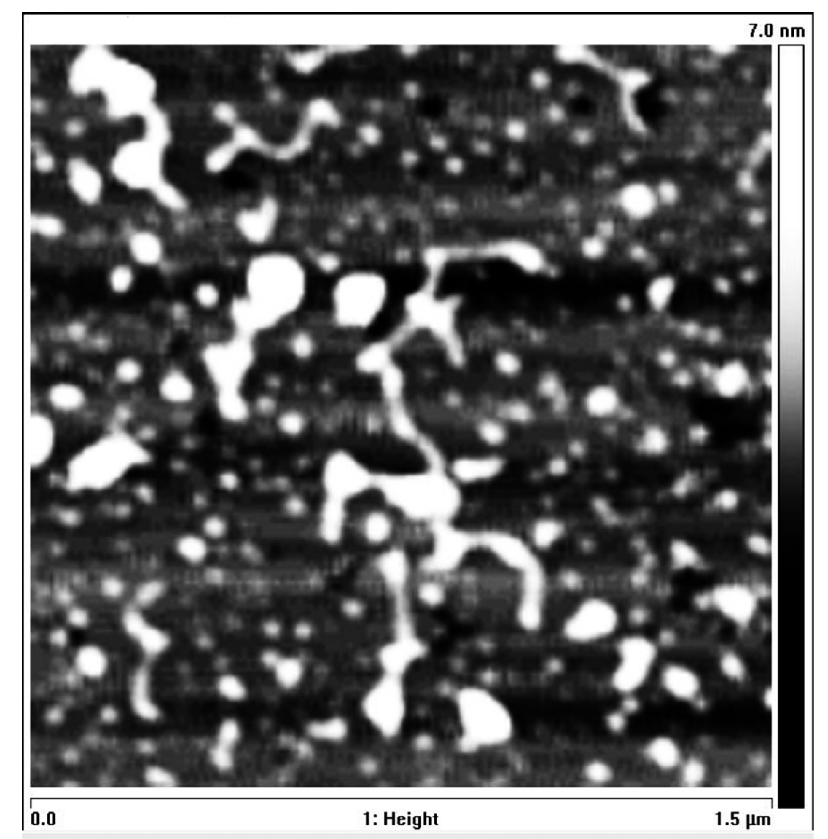

(a)

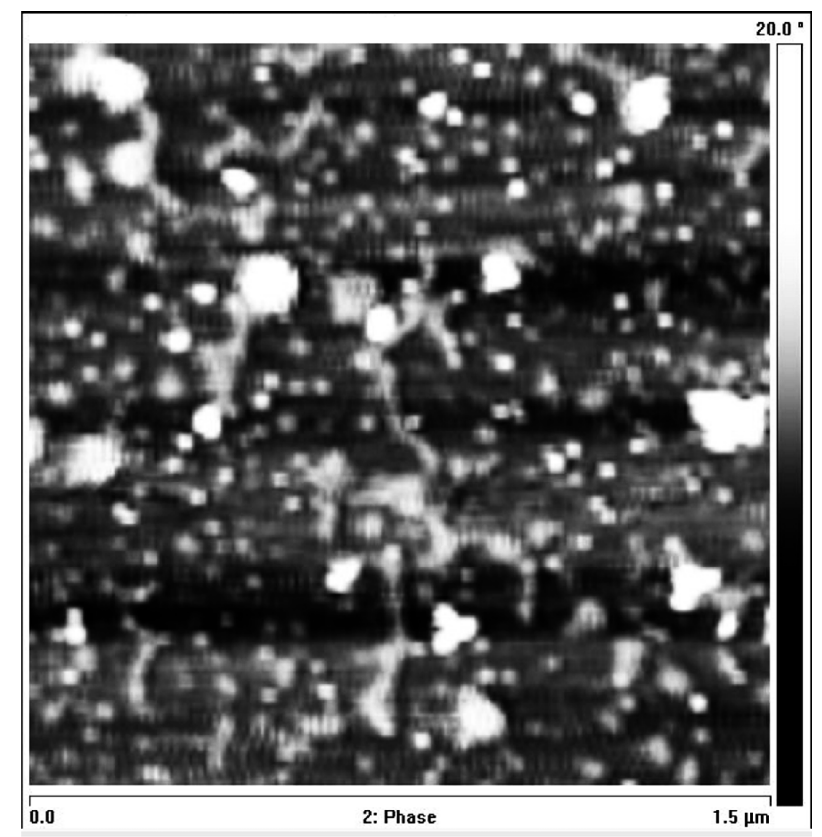

(b)

Fig. 1. Two-dimensional SPM images of (a) topography and (b) phase distribution for DNA layer self-assembled from colloidal solution on the mica surface than rinsed in distilled water and dried.

Fig. 1(a) are typical of the samples based on mica substrates with DNA on it (see, e. g., [19, 27, 28]). Considering the influence of tip diameter on the dimensions in horizontal axis, thickness of the threads approximately represents diameter of the thread like DNA structures and is equal to about $7-8 \mathrm{~nm}$. Length of these structures varies between 0.5 and $2 \mu \mathrm{m}$. The surface density of these structures seems being approximately the same over surfaces of the same sample as well as in several reference samples obtained under similar conditions. Separated DNA structures were detected on the surfaces after empirical selection of acceptable source by sequential dilution of the initial colloidal solution with DNA.

SPM images in the main phase mode (Fig. 1(b)) discriminate between compositions of the objects on the basis of friction and viscosity. Very bright objects in Fig. 1(b) are attributed to precipitates of salts from the solution. Light grey objects are much softer than the bright ones and display the biomolecular structures. The origin of the light grey spots in Fig. 1(b) that correspond to the ball like objects in Fig. 1(a) are not determined in present stage of investigation. It can be supposed that the ball like objects in SPM images represent agglomerates of biomolecules remaining from the solutions used in the DNA purification technology.

Typical topography of the metallized DNA layer on mica substrate is shown by the SPM image of heights in Fig. 2(a). The surface of the sample is covered by comparatively smooth coating (grey background in Fig. 2(a)) and separated rocks emerging from the coating or laying on the top of it (bright spots). Height of the objects varies between 7 and $15 \mathrm{~nm}$. Some of these objects are evidently different from the background coating as it can be proved by SPM image constructed from the phase measurements (Fig. 2(b)). The bright spots in Fig. 2(b) are associated with higher friction and can be harder than the background coating. Since Ag nanoparticles are deposited from colloidal solution on the top of the structure, it seems reasonable to accept the bright spots as visualized Ag based nanoobjects in the SPM images in Fig. 2. It follows from careful comparison of the height and phase images in Fig. 2 (a) and (b), respectively, that only part of separated objects can be supposed to be made of a more dense matter than the background. Part of clearly identifiable peaks in the SPM presentation of the heights looks like the background in the phase map in Fig. 2(b). The differences between mechanical properties of separated objects in Fig. 2 (a) and (b) can be explained assuming the presence of a thin coating of remaining substance from colloidal solution on the Ag nanoparticles even if Ag balls rise above the surface.

The separated objects in the Ag-coated DNA layer on mica were also analysed by EFM mode of the SPM. Typical surface potential distribution over the scanned area is illustrated by electrical force sensitive phase images in Fig. 3. The area in Fig. 3 is the same as the 


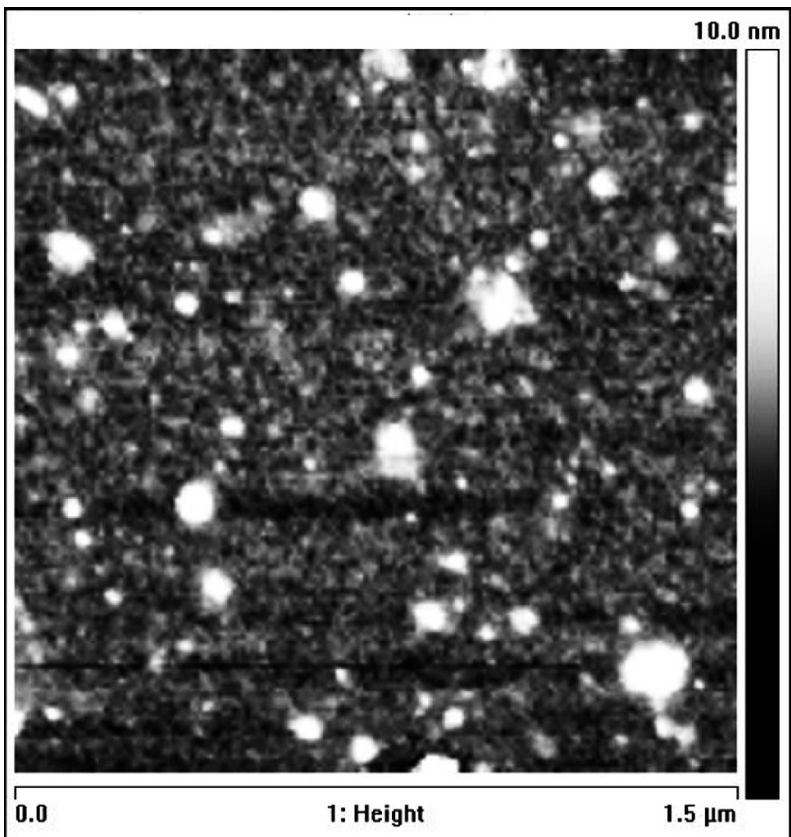

(a)

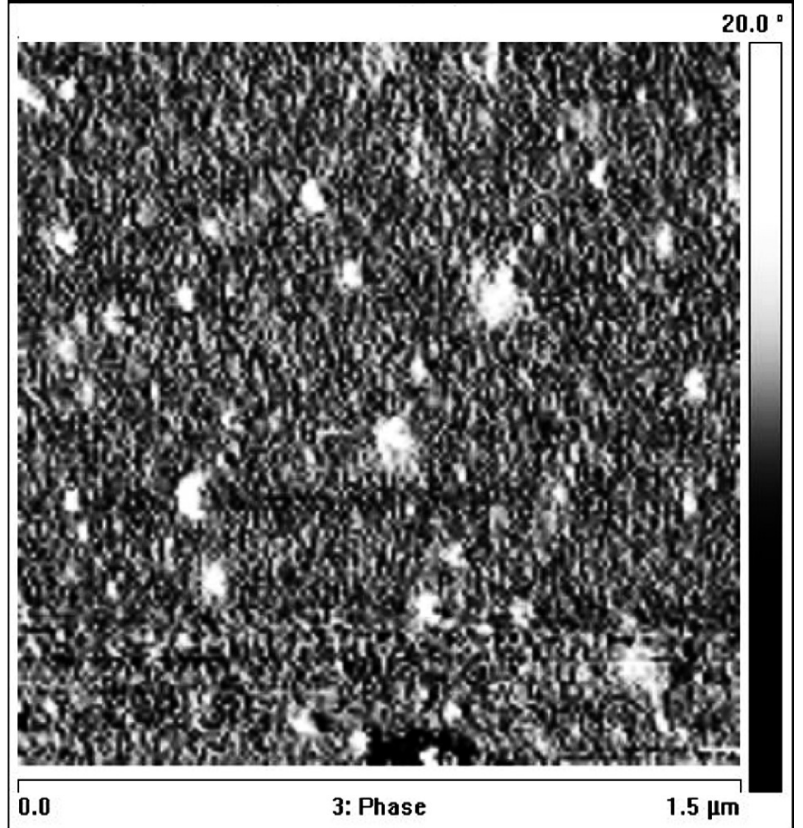

(b)

Fig. 2. Two-dimensional SPM images of (a) topography and (b) phase distribution for a layer composed of the APTES and Ag nanograins on a mica substrate when the base voltage in the EFM mode scanning is $+1 \mathrm{~V}$.

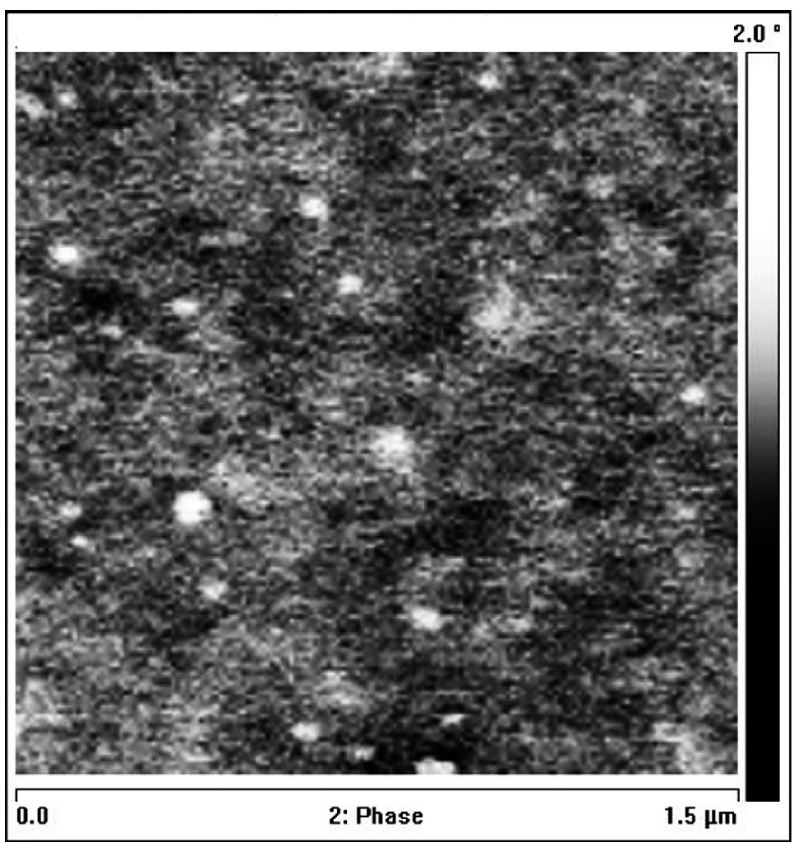

(a)

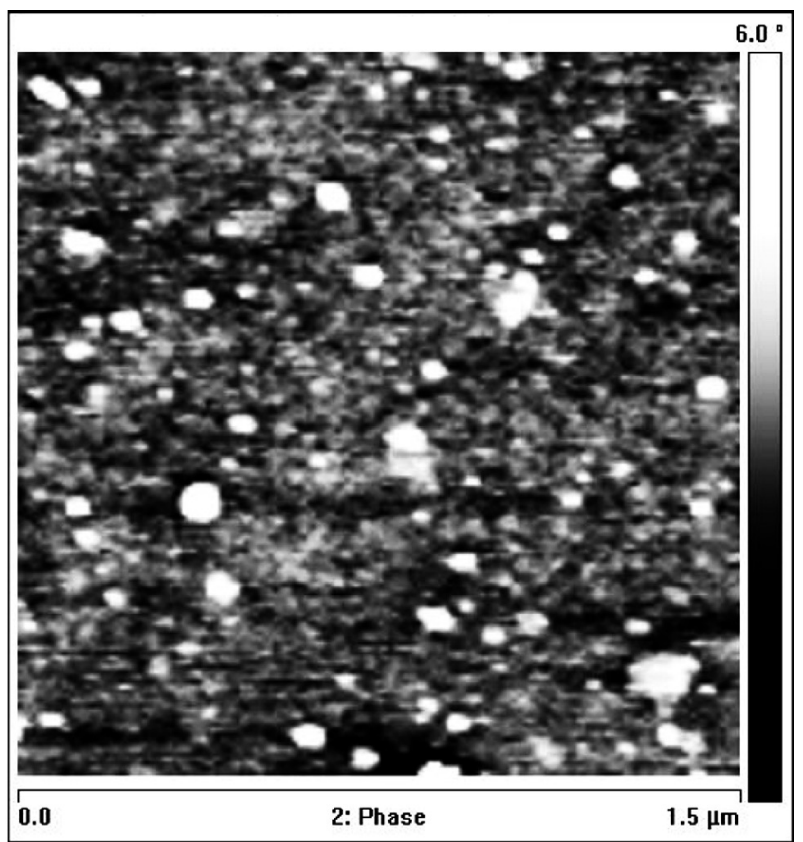

(b)

Fig. 3. Two-dimensional SPM images of the electric force phase distribution for a layer composed of the DNA and Ag nanograins on a mica substrate with the base voltage (a) $+1 \mathrm{~V}$ and (b) $+10 \mathrm{~V}$.

area in Fig. 2. In Fig. 3, the bright spots represent the areas of locally charged domains of the sample surface. The two images in Fig. 3 (a) and (b) were obtained for the same area of the sample between which and the tip the DC voltage difference is equal to +1 and $+10 \mathrm{~V}$, respectively. A larger DC voltage difference between the tip and the sample leads to a larger amplitude of oscillations of cantilever and, consequently, to a higher sensitivity to the charged domains. In Fig. 3(a), bright spots of low density can be associated with completely clean Ag nanoparticles on the top of DNA layer. Metallic nanoparticles that are partly or even completely cov- 
ered by an isolating coating are explicitly displayed in the EFM phase image if the applied DC voltage is high enough. Based on comparison of the topography, standard phase and the EFM phase images, it seems reasonable to suppose that $\mathrm{Ag}$ nanoparticles are completely covered by remaining substance from dried colloidal solution on the mica substrate and only part of the nanoparticles are clear of this coating.

Specific multicomponent constructions self-assembled on the Si substrates after final stage in the $\mathrm{Ag} /$ DNA / APTES / $\left[\mathrm{SiO}_{2} /\right] \mathrm{Si}$ technology. These structures were traced by the SPM measurements. Typical images of SPM height map are shown in Fig. 4. The two-dimensional representation of topography was obtained for the same sample in as-prepared samples and after rinsing in water ultrasound bath. Chains of nanoparticles seem to be common feature of arrangement of the surfaces in both SPM images in Fig. 4. Several well-ordered multicomponent objects in which $\mathrm{Ag}$ nanoparticles form lines are typically traced in the square $1.5 \times 1.5 \mu \mathrm{m}^{2}$ on the surface of the samples. The shape of the lines seems similar to DNA images obtained for the mica based samples.

The sizes of nanoparticles in the combined coatings were dependent on the final rinsing of the samples. The SPM image in Fig. 4(a) represents topography of the samples after self-assemblage of the top Ag nanoparticles based layer, while the image in Fig. 4(b) shows the surfaces after special final rinsing of the samples. The

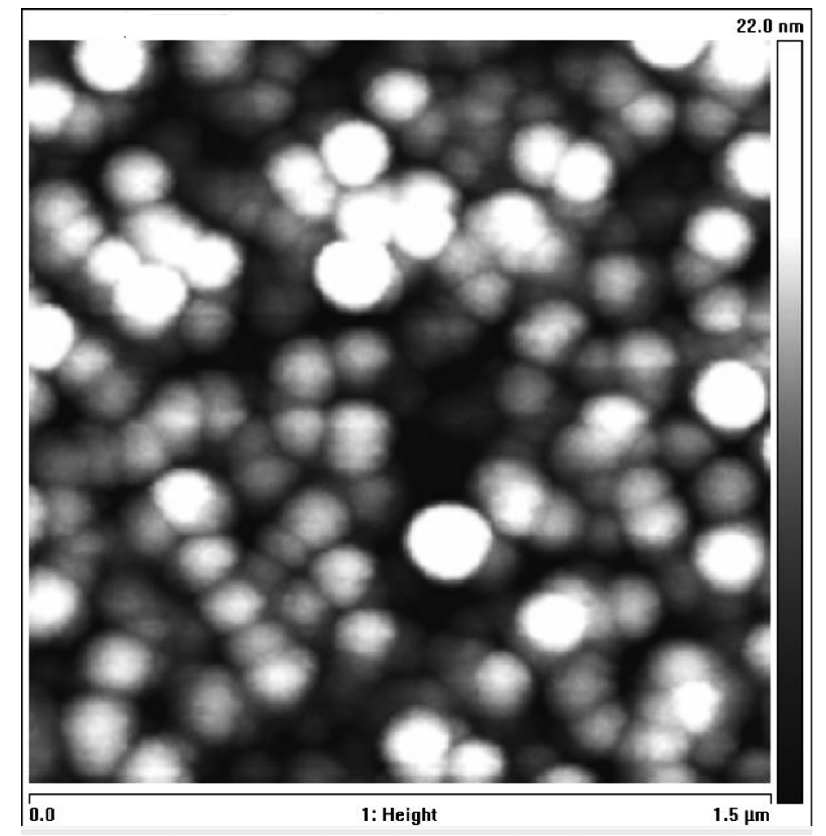

(a) particles are clearly smaller on the surfaces after rinsing of samples. The effect of size reduction can be understood if encapsulation of $\mathrm{Ag}$ nanoparticles within PVP coating is considered. It seems reasonable to suppose that several nanoparticles are trapped within single PVP bubble. Therefore comparatively large nanoparticles are visualized on the surfaces of as-prepared samples. Rinsing in water removes the PVP coating and clean Ag nanoparticles are displayed. The well-ordered structure is determined by self-assemblage of Ag nanoparticles, therefore the in-line arranged objects are traced on the surfaces of the samples before and after rinsing.

\subsection{Optical studies}

The optical studies were used for characterization of hybrid samples and identification of the components in complex structures due to their contribution to optical response. For this purpose, the optical response of separate components has been primarily investigated.

The spectral dependence of the optical response of APTES layer deposited on Si substrate by immersion technique was found to be well described by standard dielectric function of $\mathrm{SiO}_{2}$ [26]. However, the weight factor varied in the range of $0.5-1.0$ indicating the porosity of APTES layer, which is known [16] to be dependent on technological regime of formation.

The spectral dependence of the ellipsometric parameters $\Psi$ and $\Delta$ for the hybrid sample Ag/APTES / Si

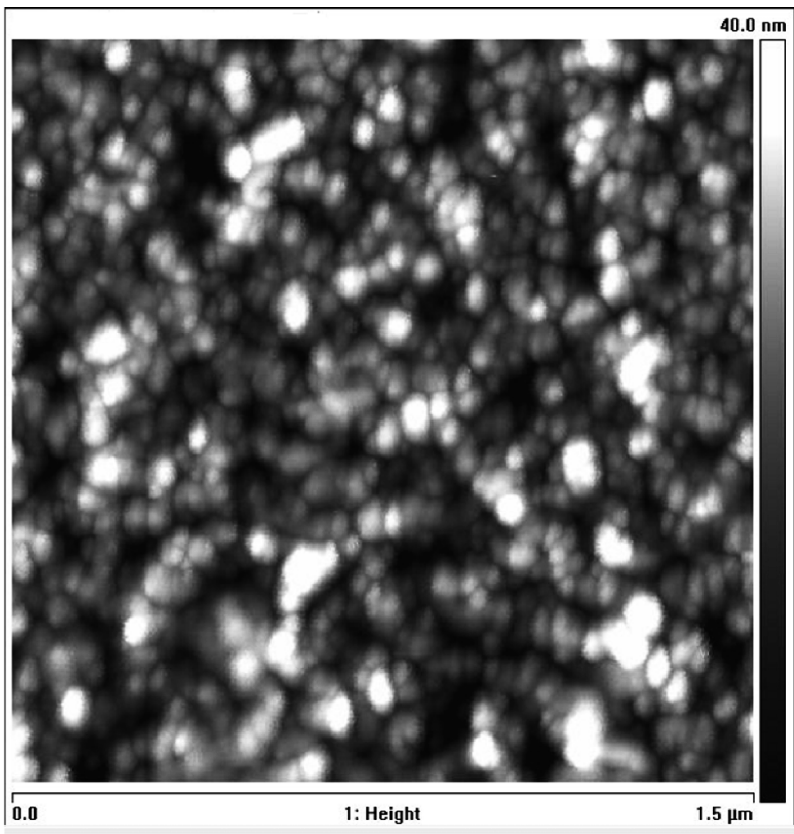

(b)

Fig. 4. Two-dimensional SPM images of topography for the multilayer samples based on Si substrates modified with the APTES covered by DNA layer and additional layer of Ag nanoparticles in (a) as-prepared state and (b) after rinsing in ethanol. 


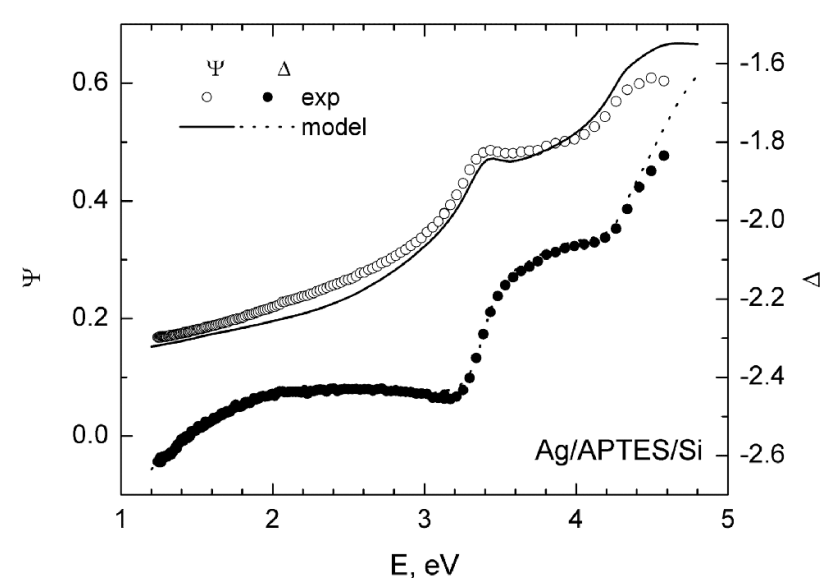

(a)

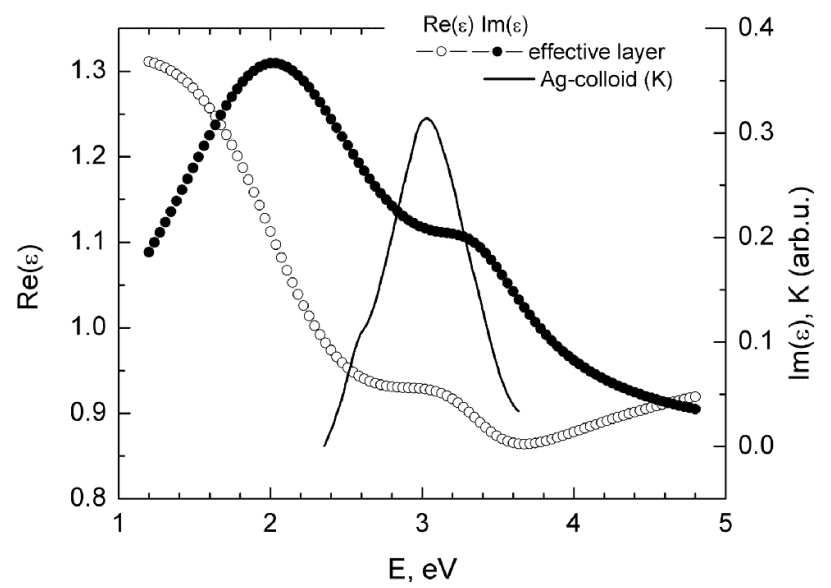

(b)

Fig. 5. (a) Experimental (points) and modelled (curves) of ellipsometric parameters $\Psi$ and $\Delta$ for the sample Ag / APTES / Si and (b) dielectric function spectra of the effective surface layer obtained from the fitting procedure as compared with the absorption spectrum of colloidal solution of Ag nanoparticles.

was fitted by the optical response of one effective layer (Fig. 5(a)) on the APTES-modified Si substrate. According to the model calculations for this sample, the thickness of the effective layer and APTES film was 5.3 and $11.5 \mathrm{~nm}$, respectively. The spectral dependence of the dielectric function for the effective layer (Fig. 5(b)) possesses two features. The low-energy peak at $\sim 2.2 \mathrm{eV}$ can be attributed to the residual material of the solution containing the PVP-coated Ag nanoparticles. However, the peak can be also due to the interparticle dipole-dipole couplings of nanoparticles on solid substrates [29]. The peak at $\sim 3.4 \mathrm{eV}$ is related to the surface plasmon resonance of metal nanoparticles [30] and corresponds to the absorption peak of $\mathrm{Ag}$ colloidal solution (Fig. 5(b)). The higher-energy shift of the peak in hybrid sample with respect to that in the

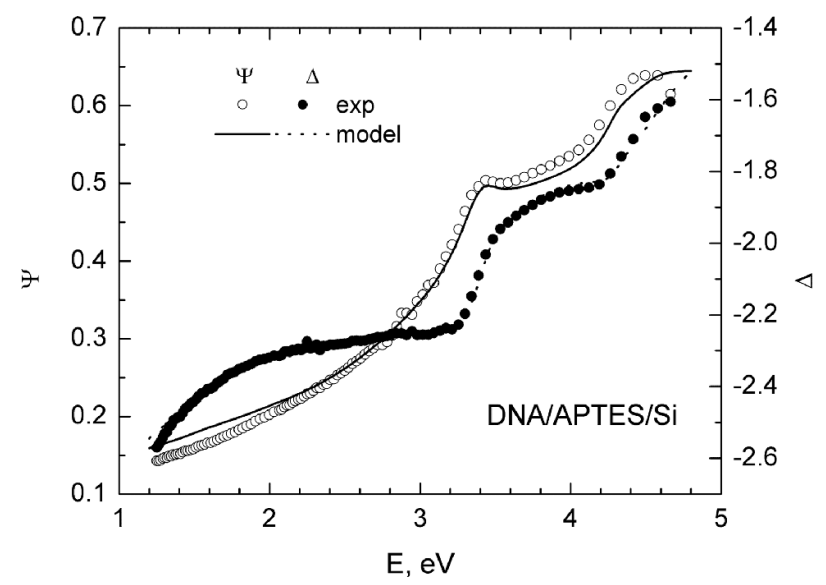

(a) colloidal solution can be due to a reduced average size of Ag nanoparticles.

Figure 6 illustrates the data for the hybrid sample DNA / APTES / Si. As seen from Fig. 6(a), the experimental data are well described by the model of two layers of thickness 25 and $13 \mathrm{~nm}$ simulating the optical response of DNA and APTES, respectively. The dielectric function of the surface layer deposited on APTES (Fig. 6(b)) has shown two optical features. The lowerenergy peak at $\sim 2.3 \mathrm{eV}$ is assumed to be due to the salts from the DNA-solution. The higher-energy peak at $4.6 \mathrm{eV}$ agrees well with the electronic excitation of DNA [31], which is represented by the main peak at $4.9 \mathrm{eV}$ and subsidiary one at $4.4 \mathrm{eV}$.

The optical response of the complex hybrid sample $\mathrm{Ag} / \mathrm{DNA}$ / APTES / Si is quite complicated because of interference pattern which manifests itself along with

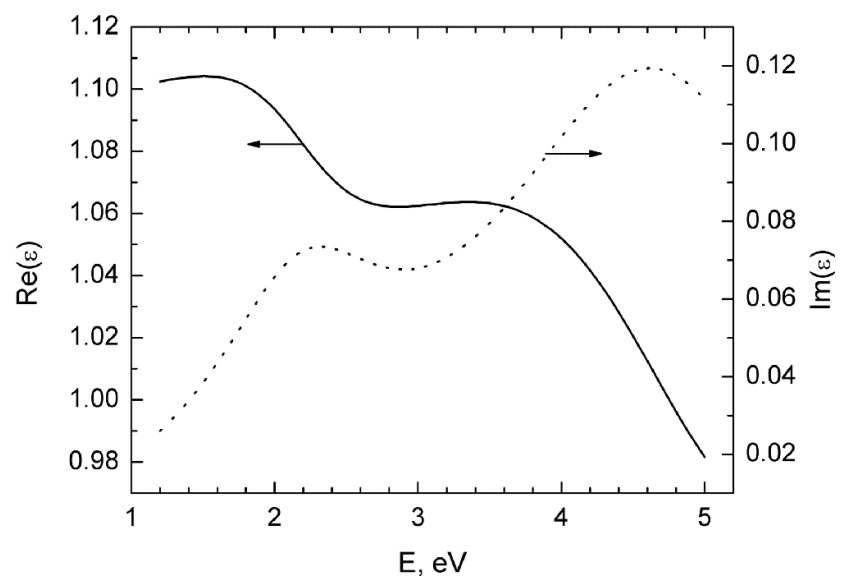

(b)

Fig. 6. (a) Experimental (points) and modelled (curves) of ellipsometric parameters $\Psi$ and $\Delta$ for the sample DNA / APTES / Si and (b) dielectric function spectra of the effective surface layer obtained from the fitting procedure. 


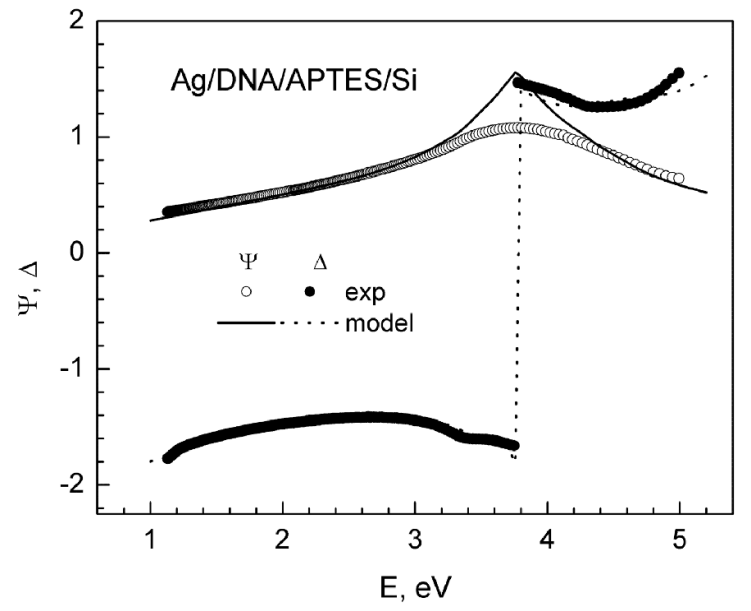

(a)

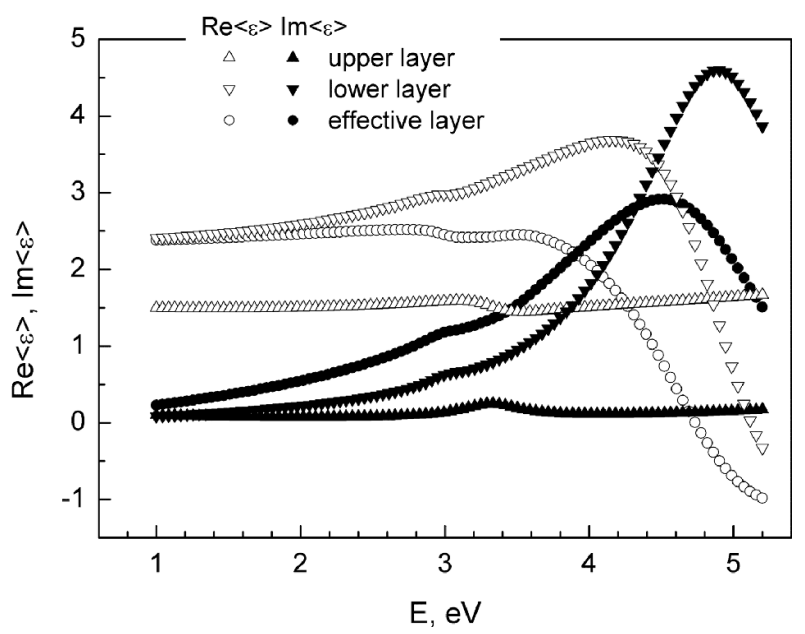

(b)

Fig. 7. (a) Experimental (points) and modelled (curves) of ellipsometric parameters $\Psi$ and $\Delta$ for the sample Ag/DNA/APTES / Si and (b) dielectric function spectra of the upper, lower, and effective surface layer obtained from the fitting procedure.

the contribution of absorbing non-homogeneous surface layer. In order to trace the spectral dependence of the phase of the light reflected from hybrid sample, additional measurements of the phase have been performed making use of the ellipsometer with photoelastic modulator of light polarization. Taking into account the results of the phase measurements and ellipsometric data obtained on the reference samples, a multilayer model was developed which described the experimental data for complex hybrid sample (Fig. 7(a)). The model simulated the optical response of three layers on Si substrate: (i) two surface layers of thickness $22 \mathrm{~nm}$ (upper sublayer) and $4.5 \mathrm{~nm}$ (lower sublayer), each approximated by Lorentzian lines, and (ii) APTES layer of thickness $49.5 \mathrm{~nm}$, the contribution of which was assumed to be the same as for silica [26]. The spectral dependence of the dielectric function of the upper two sublayers along with that for resultant effective layer is shown in Fig. 7(b). As seen from Figs. 5(b), 6(b), and 7(b), the dielectric function of upper sublayer can be interpreted by dominating contribution of $\mathrm{Ag}$ nanoparticles, whereas the optical response of the lower sublayer is mainly caused by DNA, though some contribution of Ag nanoparticles has also been detected. Additional model calculations of the direct optical response of the complex system $\mathrm{Ag} / \mathrm{DNA} / \mathrm{SiO}_{2} / \mathrm{Si}$ agree well with experimental data.

The optical studies have confirmed the results of structural investigations. The optical response of the DNA molecules integrated on the APTES-modified surface of Si substrate along with the contribution $\mathrm{Ag}$ nanoparticles were clearly resolved in the ellipsometric spectra and were well simulated by model calculations.

\section{Discussions}

Quantitative analysis of the surface topology obtained by SPM scanning can be based on processing of digitized profiles of the scans. It was demonstrated in various studies [32-34] that some features of the surfaces structures can be described by parameters of the power spectral density (PSD) function derived from the AFM surface profile data.

In our experiment the frequency distribution for a digitized profile of length $L$, consisting of $N$ points sampled at intervals of $d_{0}$, is described by formula

$$
\begin{gathered}
\operatorname{PSD}(f)=\frac{2 d_{0}}{N}\left|\sum_{n=1}^{N} \mathrm{e}^{\frac{\mathrm{i} 2 \pi}{N}(n-1)(m-1)} z(n)\right|^{2} \\
\text { for } f=\frac{m-1}{N d_{0}},
\end{gathered}
$$

in which frequencies $f$ range from $1 / L$ to $(N / 2) / L$. The PSD functions obtained for our samples characterized by the SPM images in Fig. 4 are illustrated in Fig. 8. The PSD dependences on frequency are similar to those typically obtained for the samples in which thin layers are deposited on smooth substrate [32-35].

It was shown in [35] that PSD of a thin film coating can be described by a sum of PSD of the substrate and the PSD of the pure film. The PSD analytical model includes the mathematical term describing the overall roughness contribution from the substrate (dominated by fractals) and pure film. PSD of the substrates with 


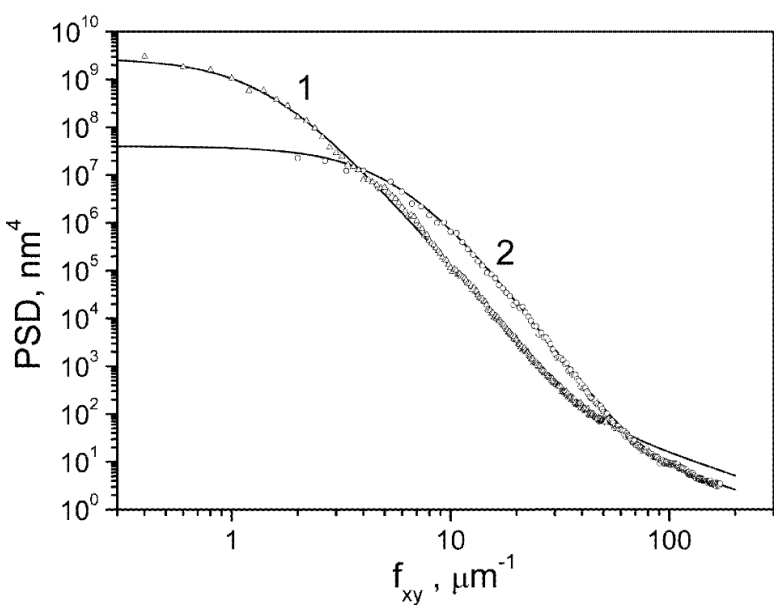

Fig. 8. The PSD function obtained from the SPM topography data in Fig. 4 (points) for the samples before (1) and after rinsing (2). Lines are model calculations explained in the text.

spatial frequencies $f$ mostly follows a fractal model, which obeys the inverse power law $[32,35]$ similar to

$$
\operatorname{PSD}_{\text {fractal }}(f: K, \nu)=\frac{K}{f^{\nu+1}} .
$$

The intrinsic surface parameters describing such fractal-like surfaces are spectral strength $K$ and spectral indices $\nu$. The formula (5) is acceptable for the highly finished surfaces that can be assumed as self-affine. For these surfaces fractal analysis can be applied using $D$ as the fractal dimension. The fractal dimension $D$ can be related to the experimental results by formula $[32,35]$

$$
D=\frac{7-(\nu+1)}{2}=\frac{6-\nu}{2}, \quad \text { with } 0<\nu<2 .
$$

The PSD function of pure film can be described using the $k$-correlation model also called the $A B C$ model $[32,33,35]$. Based on this model, the PSD function is described by formula

$$
\operatorname{PSD}_{A B C}=\frac{A}{\left(1+B^{2} f^{2}\right)^{(C+2) / 2}},
$$

with $A, B, C$ being the function parameters and the value of $C$ greater than 2 . This model satisfactorily describes random rough surfaces over large length scales. If calculated according to (7), a "knee" appears in the PSD function. This specific shape of the function is determined by $B$, which is equal to the correlation length. At small $f$ values well below the knee the PSD is determined by $A$, and at high $f$ values, beyond the knee, the surface is fractal and the PSD function is determined by C.

Sum of the terms (5) and (7) was used to calculate theoretical curves shown by lines in Fig. 8. The parameters in (5) and (7) were varied until theoretical curves fitted experimental dependences represented by points in Fig. 8. The PSD model satisfactorily characterized the topographies of our samples. The fractal roughness components of substrate and intrinsic film roughness have been derived from this modelling. It can be emphasized here that the first term related to the substrate and substrate-induced effect is described by almost the same parameters for as-prepared and rinsed samples. For the substrate the fractal dimension equal to about $D=2.7$ is obtained, while the spectral strength $K$ is about $10^{4}$. The parameters of the second term representing the $A B C$ model are dependent on the technology of the coating. For as-prepared coatings the parameters were $A=2.8 \cdot 10^{9}, B=0.68, C=4.2$. After rinsing the model description of the PSD function gives $A=4 \cdot 10^{7}, B=0.17, C=4.95$. It must be pointed here that applied voltage in the EFM mode does not change the PSD function. Since the parameter $B$ is proportional to the correlation length representing the mean grain size in the coating, the model analysis of PSD function quantitatively defines reduced dimensions of the nanoobjects of the layer after sample rinsing. Considering the characterization of Si substrate, flat well-prepared surfaces have to be described by $D=$ 2 . Higher $D$ magnitudes can be explained by comparatively large roughness of the surface. It can be supposed that technological procedures used for formation of the multicomponent coating seem to be damaging the surfaces of the Si substrates that initially have been characterized by variations in height of about $1-2 \mathrm{~nm}$.

\section{Conclusions}

The self-arranged ordered DNA structures decorated by Ag nanoparticles are effectively formed on the $\mathrm{Si}$ surface modified by APTES. On these substrates, detailed SPM structural studies revealed the main regularities in the self-organization process of DNA structures. The investigations have shown the commonalities and some specific features in the hybrid structures on smooth mica surface and modified Si substrates. Absence of regular structures on mica surfaces has proved that binding force of DNA to the surfaces is much lower in mica-DNA system compared to the hybrid structure based on modified Si substrates. Spectroscopic ellipsometry measurements were shown to be effective tool for characterization of complex hybrid samples Ag / DNA / APTES / Si. The contributions to optical response due to components in hybrid samples can be separated by detailed ellipsometric studies. 


\section{Acknowledgements}

The study is supported by the Lithuanian State Science and Studies Foundation (project registration number C-07015). The authors are also grateful to Dr Kornelijus Stankevičius and his group for expressed interests and DNA samples in this work.

\section{References}

[1] I. Willner, B. Willner, and E. Katz, Biomoleculenanoparticle hybrid systems for bioelectronic applications, Bioelectrochem. 70, 2-11 (2007).

[2] T. Liedl, T.L. Sobey, and F.C. Simmel, DNA-based nanodevices, Nanotoday 2, 36-41 (2007).

[3] F.L. Yap and Y. Zhang, Protein and cell micropatterning and its integration with micro/nanoparticles assembly, Biosensors Bioelectron. 22, 775-788 (2007).

[4] Q. Huo, A perspective on bioconjugated nanoparticles and quantum dots, Colloids Surf. B 59, 1-10 (2007).

[5] H.R. Luckarift, S. Balasubramanian, S. Paliwal, G.R. Johnson, and A.L. Simonian, Enzymeencapsulated silica monolayers for rapid functionalization of a gold surface, Colloids Surf. B 58, 28-33 (2007).

[6] D.N. Woolfson and M.G. Ryadnov, Peptide-based fibrous biomaterials: Some things old, new and borrowed, Curr. Opinion Chem. Biol. 10, 559-567 (2006).

[7] A. Wu, W. Cheng, Z. Li, J. Jiang, and E. Wang, Electrostatic-assembly metallized nanoparticles network by DNA template, Talanta 68, 693-699 (2006).

[8] C. Peng, Yo. Song, G. Wei, W. Zhang, Z. Li, and W.-F. Dong, Self-assembly of $\lambda$-DNA networks/Ag nanoparticles: Hybrid architecture and active-SERS substrate, J. Colloid Interface Sci. 317, 183-190 (2008)

[9] V. Lavalley, P. Chaudouet, and V. Stambouli, An atomic force microscopy study of DNA hairpin probes monolabelled with gold nanoparticle: Grafting and hybridization on oxide thin films, Surf. Sci. 601, 54245432 (2007).

[10] S. Basu, S. Jana, S. Pande, and T. Pal, Interaction of DNA bases with silver nanoparticles: Assembly quantified through SPRS and SERS, J. Colloid Interface Sci. 321, 288-293 (2008).

[11] A. Mougin, V.G. Babak, F. Palmino, E. Beche, F. Baros, D.J. Hunting, L. Sanche, and M. Fromm, TDAB-induced DNA plasmid condensation on the surface of a reconstructed boron doped silicon substrate, Surf. Sci. 602, 142-150 (2008).

[12] K. Kalyanasundaram and M. Grätzel, Applications of functionalized transition metal complexes in photonic and optoelectronic devices, Coord. Chem. Rev. 177, 347-414 (1998).
[13] J. Kobayashi, T. Hinoue, and H. Watarai, Study of adsorption of water-soluble porphyrin at glass-solution interface in the presence of cationic surfactant admicelles by means of total internal reflection spectroscopy, Bull. Chem. Soc. Jpn. 71, 1847-1855 (1998).

[14] S.B. Lei, J. Wang, Y.H. Dong, C. Wang, L.J. Wan, and C.L. Bai, STM and XRD studies of the adsorption and assembling structures of phthalocyanine and porphyrin, Surf. Interface Anal. 34, 767-771 (2002).

[15] Q. Weiping, X. Bin, Y. Danfeng, L. Yihua, W. Lei, W. Chunxiao, Y. Fang, L. Zhuhong, and W. Lu, Sitedirected immobilization if immunoglobulin $\mathrm{G}$ on 3aminopropyltriethoxysilane modified silicon wafer surfaces, Mater. Sci. Eng. C 8-9, 475-480 (1999).

[16] R. Šustavičiūtè, I. Šimkienè, J. Sabataitytè, A. Rėza, A. Kindurys, R. Tamaševičius, and J. Babonas, Formation and investigation of porous $\mathrm{SiO}_{2}$ films on $\mathrm{Si}$, Lithuanian J. Phys. 44, 465-476 (2004).

[17] F.J. Giessibl, Advances in atomic force microscopy, Rev. Mod. Phys. 75, 949-983 (2003).

[18] B. Anczykowski, B. Gotsmann, H. Fuchs, J.P. Cleveland, and V.B. Elings, How to measure energy dissipation in dynamic mode atomic force microscopy, Appl. Surf. Sci. 140, 376-382 (1999).

[19] M. Argaman, R. Golan, N.H. Thomson, and H.G. Hansma, Phase imaging of moving DNA molecules and DNA molecules replicated in the atomic force microscope, Nucleic Acids Res. 25, 4379-4384 (1997).

[20] B. Gady, D. Schleef, R. Reifenberger, D. Rimai, and L.P. DeMejo, Identification of electrostatic and van der Waals interaction forces between a micrometer-size sphere and a flat substrate, Phys. Rev. B 53, 8065-8070 (1996)

[21] M. Lee, W. Lee, and F.B. Prinz, Geometric artefact suppressed surface potential measurements, Nanotechnol. 17, 3728-3733 (2006).

[22] R.W. Stark, N. Naujoks, and A. Stemmer, Multifrequency electrostatic force microscopy in the repulsive regime, Nanotechnol. 18, 065502-1-7 (2007).

[23] G.-J. Babonas, A. Niilisk, A. Reza, A. Matulis, and A. Rosental, Spectroscopic ellipsometry of $\mathrm{TiO}_{2} / \mathrm{Si}$, Proc. SPIE 5122, 50-55 (2003).

[24] R. Tamaševičius, I. Šimkienè, A. Rėza, I. Blažys, and G.J. Babonas, Magnetic circular dichroism of iron porphyrin, Proc. SPIE 6596, 65961E-1-6 (2007).

[25] D. Bedeaux and J. Vlieger, Optical Properties of Surfaces (Imperial College Press, Singapore, 2004).

[26] SOPRA database: www . sopra-sa.com .

[27] M. Kobayashi, K. Sumitomo, and K. Torimitsu, Realtime imaging of DNA-streptavidin complex formation in solution using a high-speed atomic force microscope, Ultramicroscopy 107, 184-190 (2007).

[28] F. Moreno-Herrero, P. Herrero, F. Moreno, J. Colchero, C. Gomez-Navarro, J. Gomez-Herrero, and A.M. Bar, Topographic characterization and electrostatic re- 
sponse of M-DNA studied by atomic force microscopy, Nanotechnol. 14, 128-133 (2003).

[29] B. Choi, H.-H. Lee, S. Jin, S. Chun, and S.-H. Kim, Characterization of the optical properties of silver nanoparticle films, Nanotechnol. 18, 075706-1-5 (2007).

[30] U. Kreibig and M. Vollmer, Optical Properties of Metal Clusters (Springer, Berlin, 1995).

[31] B.I. Kankia, Optical absorption assay for strandexchange reactions in unlabeled nucleic acids, Nucleic Acid Res. 32, e154-1-6 (2004).

[32] N.K. Sahoo, S. Thakur, M. Senthilkumar, D. Bhattacharyya, and N.C. Das, Reactive electron beam evaporation of gadolinium oxide optical thin films for ul- traviolet and deep ultraviolet laser wavelengths, Thin Solid Films 440, 155-168 (2003).

[33] N.K. Sahoo, S. Thakur, and R.B. Tokas, Fractals and superstructures in gadolinia thin film morphology: Influence of process variables on their characteristic parameters, Thin Solid Films 503, 85-95 (2006).

[34] S. Jakops, A. Duparre, and H. Truckenbrodt, AFM and light scattering measurements of optical thin films for applications in the UV spectral region, Int. J. Machine Tools Manufact. 38, 733-739 (1998).

[35] X. Kuang and Z. Zhu, Fractal analysis and simulation of surface roughness of ceramic particles for composite materials, Appl. Composite Mater. 4, 69-81 (1997).

\title{
DNR SĄSAJOS SU DAUGIAKOMPONENČIAIS DARINIAIS Si PAVIRŠIUJE TYRIMAS SKENUOJANČIOJO ZONDO MIKROSKOPU IR OPTINIAIS METODAIS
}

\author{
V. Bukauskas, J. Babonas, A. Rèza, J. Sabataitytė, I. Šimkienė, A. Šetkus \\ Puslaidininkiu fizikos institutas, Vilnius, Lietuva
}

\begin{abstract}
Santrauka
Darinių su DNR molekulèmis susitvarkymas ant švaraus žèručio ir specialiai apdoroto Si paviršiu yra tirtas skenuojančiojo zondo mikroskopu (SZM) ir spektroskopine elipsometrija (SE). Kambario temperatūroje DNR junginiai nusodinami ant kietojo paviršiaus iš koloidinių tirpalų. Kietieji padèklai su biomolekulemis taip pat padengiami Ag nanodalelių sluoksniu. Savitvarkių darinių paviršiaus
\end{abstract}

atvaizdas gaunamas naudojant ịvairius SZM režimus. Taip pat tiriama optinio atsako priklausomybè nuo daugiakomponenčio hibridinio darinio sandaros. Specifiniai pokyčiai, stebimi optiniame atsake, atsiranda dèl DNR molekulių ir Ag nanodalelių susijungimo savitvarkiame hibridiniame darinyje ant Si paviršiaus. Aptariamos tvarkingai ant kietojo paviršiaus susirikiavusių darinių charakteristikos, siejant jas su DNR ir Ag nanodalelių susijungimo ypatumais. 